\title{
ETEOCLES Y POLINICES EN LOS SIMILES DE LA TEBAIDA DE ESTACIO
}

Antonio Luque Lozano

Con el abundante uso de las comparaciones, Estacio consigue definir el carácter y comportamiento de los diferentes participantes en la Tebaida. El poder caracterizador de los símiles estacianos es superior al de los de Virgilio; en la Eneida, sólo los personajes muy destacados (Eneas y Turno) y algún guerrero (Mecencio) y elementos como la guerra y los pueblos, reciben comparaciones coherentes entre si ${ }^{1}$. En cambio, en la Tebaida casi todos los símbolos están organizados en una red imaginativa estrechamente relacionada con los términos a que se aplica. A modo de ejemplo, veremos cómo quedan caracterizados Eteocles y Polinices en las comparaciones de la Tebaida.

Los dos hermanos cuya rivalidad por el trono de Tebas llevó a dos pueblos (el argivo y el tebano) a la guerra, tienen una caracterización peculiar en los símiles con que se les ilustra. Su comportamiento, a diferencia del de los otros guerreros, no es brillante en ningún caso; lo que destaca continuamente es su mediocridad: ha de ser siempre Tideo (el principal héroe argivo, tomado como yerno por Adrasto al mismo tiempo que Polinices) el más esforzado y el impulsor de la guerra.

Eteocles y Polinices son objeto juntos de 6 comparaciones: en el Libro I hay dos de ellas; las otras son de su enfrentamiento final. La primera imagen que se les aplica ilustra sus desavenencias por el trono, igualándoseles a novillos inexpertos en el arado que tiran cada uno hacia un lado:

sic ubi delectos per torva armenta iuvencos agricola imposito sociare adfectat aratro, illi indignantes, quis nondum vomere multo ardua nodosos cervix descendit in armos, in diversa trahunt atque aequis vincula laxant viribus et vario confundunt limite sulcos.

(I, 131-136)

1 Cf. Hornsby, R.A., Pattern of Action in the Aeneid. An Interpretation of Vergil's Epic Similes, Iowa, 1970; González Vázquez, J., La imagen en la poesía de Virgilio, Granada, 1980, pp. 197-306. 
Se trata de un símil original que no encontramos en ningún autor anterior. Con ésta, contrasta otra imagen en que Polinices abandona la lucha tras la muerte de Tideo como un toro que pierde su compañero de yugo y no soporta tener que arrastrar del arado:

ducitur amisso qualis consorte laborum deserit inceptum media inter iugera sulcum taurus iners colloque iugum deforme remisso parte trahit, partem lacrimans sustentat arator.

(IX, 82-85)

Esa unión amistosa entre Tideo y Polinices —opuesta a la desavenencia de los auténticos hermanos- es reiterada a lo largo y ancho de la obra; su amistad se compara a la de Teseo y Pirítoo y a la de Pílades y Orestes:

hanc perhibent post vulnera iunctis

esse fidem, quanta partitum extrema protervo

Thesea Pirithoo, vel inanem mentis Oresten opposito rabidam Pylade vitasse Megaeram.

(I, 474-477)

Y la realidad es que con insistencia aparece Tideo más empeñado en la guerra que el propio Polinices (como si de algo suyo se tratara: II, 364-366); y Polinices está siempre necesitado de Tideo. Las comparaciones con el toro siguen: Polinices es como el toro que, vencido por otro, no deja de pensar en sus pastos y en su novilla; así está el nostálgico por el trono:

veluti dux taurus amata

valle carens, pulsum solito quem gramine victor

iussit ab erepta longe mugire iuvenca,

cum profugo placuere tori cervixque recepto

sanguine magna redit fractaeque in pectora quercus,

bella cupit pastusque et capta armenta reposcit

iam pede, iam cornu melior (pavet ipse reversum

victor, et attoniti vix agnovere magistri).

(II, 323-330)

Esto nos hace comprender que el combate final entre los dos se prepare como el del novillo reinante y el toro que fue antiguo rey de la manada:

sic ubi regnator post exulis otia tauri

mugitum hostilem summa tulit aure iuvencus

agnosvitque minas, magna stat fervidus ira

ante gregem spumisque animos ardentibus efflat,

nunc pede torvus humum, nunc cornibus aëra findens;

horret ager, trepidaeque exspectant proelia valles.

(XI, 251-256)

Esta imagen tiene ecos de aquélla del Libro XII de la Eneida, que refleja la lucha final de Eneas y Turno como la de dos toros: 
ac velut ingenti Sila summove Taburno
cum duo conversis inimica in proelia tauri
frontibus incurrunt, pavidi cessere magistri,
stat pecus omne metu mutum, mussantque iuvencae
quis memori imperitet, quem tota armenta sequantur;
illi inter sese multa vi vulnera miscent
cornuaque obnixi infigunt et sanguine largo
colla armosque lavant, gemitu nemus omne remugit.

(Aen. XII, 715-722)

En el Libro I de la Tebaida se compara la rivalidad de los hermanos con el enfrentamiento de los vientos en alta mar, que hace vacilar una nave:

qualiter hinc gelidus Boreas, hinc nubifer Eurus

vela trahunt, nutat mediae fortuna carinae ...

(I, 193-194)

En este pasaje, la nave designa a la ciudad que se tambalea por las discordias de sus dirigentes; es el tópico con el que se habían unido tradicionalmente la política y lo marítimo, los gobernantes y los pilotos. Ya Solón (s. IV a.C.) utilizó la imagen (frag. 11 Diehl); como tema de símiles es fácil de encontrar en la épica: en Il. II, 144-146 se agita la asamblea de argivos como el mar por el viento; Pompeyo se deja arrastrar a la batalla de Farsalia como el navegante que se entrega a los vientos, abandonando su técnica (Lucan. BC VII, 125-127); o Fabio, que presagia la guerra como el experto marino que previene las tormentas (Sil.Ital. Punica I, 687-689). Este tópico, aplicado al contexto que comentamos en Estacio, se encontraba en Sófocles (Ant. 162). Curiosamente, se compara también la amistad entre Tideo y Polinices con los vientos que se calman, estableciéndose de nuevo una relación entre ellos que no existe entre los verdaderos hermanos:

ventis ut decertata residunt

aequora, laxatisque diu tamen aura superstes

immoritur velis.

(I, 479-481)

En este campo temático, Adrasto, como buen caudillo atento a la seguridad de su pueblo cuando en la noche duermen los argivos, es comparado al piloto que vela mientras la tripulación descansa:

sic ubi per fluctus uno ratis obruta somno conticuit, tantique maris secura iuventus mandavere animas: solus stat puppe magister pervigil inscriptaque deus qui navigat alno.

(VIII, 267-270)

Frente a esta caracterización positiva, tanto Eteocles como Polinices son comparados con pilotos no vigilantes durante la tormenta; Polinices está en el camino del exilio (en una noche de tormenta) perdido como el navegante sorprendido en la noche por una tempestad: 
ac velut hiberno deprensus navita ponto, cui neque Temo piger neque amico sidere monstrat Luna vias, medio caeli pelagique tumultu stat rationis inops; iam iamque aut saxa malignis exspectat summersa vadis aut vertice acuto spumantes scopulos erectae incurrere prorae.

Cuando Adrasto lo acoge y consuela con sus palabras, es como la nave azotada por el viento que por fin avista tierra:

nec minus haec laeti trahimus solacia, quam si praecipiti convulsa Noto prospectet amicam puppis humum.

(II, 193-195)

Más adelante, en los juegos funerales, encontramos una nueva muestra de su pusilanimidad: pierde y abandona el control del carro que conduce como piloto desesperado en la tormenta que se entrega al azar:

lassa veluti ratione magister in fluctus, in saxa ruit nec iam amplius astra respicit et victam proiecit casibus artem.

(VI, 451-453)

En la otra cara, encontramos a Eteocles que descansa (mientras Polinices prepara la guerra, según dice el fantasma de Layo) como el piloto descuidado que en la tormenta no toma precauciones:

tu, veluti magnum si iam tollentibus Austris Ionium nigra iaceat sub nube magister immemor armorum versantisque aequora clavi, cunctaris.

(II, 105-108)

En esta ocasión, su temor es comparado con el del piloto perdido en la tormenta, cuando no regresan los cincuenta tebanos que mandó emboscar contra Tideo:

iam pudet incepti, iam paenitet. ac velut ille fluctibus Ioniis Calabrae datus arbiter alno nec rudis undarum (portus sed linquere amicos purior Olenii frustra gradus impulit astri), cum fragor hiberni subitus Iovis, omnia mundi claustra tonant multusque polos inclinat Orion, ipse quidem malit terras pugnatque reverti, fert ingens a puppe Notus, tunc arte relicta ingemit et caecas sequitur iam nescius undas.

(III, 22-30)

Todas estas imágenes tienen su culminación en el combate final, cuando Eteocles y Polinices caen al suelo como dos naves empujadas por la tempestad la una contra la otra en la oscuridad de la noche: 
ut nocte rates, quas nubilus Auster

implicuit, frangunt tonsas mutantque rudentes, luctataeque diu tenebris hiemique sibique, sicut erant, imo pariter sedere profundo.

(XI, 520-523)

La pelea final a la vista de todos los combatientes es tan violenta y salvaje como la de dos jabalíes que luchan ante un cazador que los ve escondido:

fulmineos veluti praeceps cum comminus egit

ira sues strictisque erexit tergora saetis:

igne tremunt oculi, lunataque dentibus uncis

ora sonant; spectat pugnas de rupe propinqua

venator pallens canibusque silentia suadet.

(XI, 530-534)

Eteocles cuenta en su actuación con más imágenes. Su carácter rabioso y enfurecido cuando es despertado por el fantasma de Layo, se compara con un tigre despertado por los cazadores:

qualis ubi audito venantum murmure tigris

horruit in maculas somnosque excussit inertes,

bella cupit laxatque genas et temperat ungues,

mox ruit in turmas natisque alimenta cruentis

spirantem fert ore virum.

(II, 128-132)

Cuando Tideo le insulta en su palacio, su conducta es vil y traidora, urdiendo la venganza como una serpiente golpeada que se revuelve:

iacto velut aspera saxo

comminus erigitur serpens, cui subter inanes

longa sitis latebras totumque agitata per artus

convocat in fauces et squamea colla venenum.

(II, 411-414)

Esa vileza queda expresada poco más abajo cuando Estacio dice de Eteocles:

Nec piger ingenium scelerum fraudis nefandae

rector eget.

$$
\text { (II, 482-483) }
$$

( «Y ni perezoso en su naturaleza criminal, el monarca no carece tampoco de abominables traiciones»). Con la serpiente se le compara otra vez, cuando Creonte la reprocha que ha sido para su propio pueblo peor que la peste o la mala tierra (ceu caelo deiecta lues inimicave telus, XI, 274) y él no replica, sino que traga los insultos como la serpiente golpeada que apresta el veneno, pero que yerra el mordisco y ha de beber su propia ponzoña:

ictus ut incerto pastoris vulnere serpens erigitur gyro longumque e corpore toto virus in ore legit; paulum si devius hostis 
torsit iter, cecidere minae tumefactaque frustra

colla sedent, irasque sui bibit ipse veneni.

(XI, 310-314)

Llama la atención que con la serpiente sólo sean comparados en la Tebaida Eteocles y Tideo, éste último cuando, recuperado de sus heridas, encabeza su ejército como serpiente que en la primavera se despoja de la vieja camisa y revive, renovando su veneno:

ceu lubricus alta

anguis humo verni blanda ad spiramina solis

erigitur liber senio et squalentibus annis

exutus laetisque minax interviret herbis:

a miser, agrestum si quis per gramina hianti

obvius et primo fraudaverit ora veneno.

(IV, 95-100)

Es clara la relación entre esta nota positiva de Tideo y — por contraste- la vileza de Eteocles en II, 411-4142.

El temor cobarde que Eteocles siente en la necromancia que ordena realizar, lo asemeja al cazador asustado por el león que él mismo ha espantado de su guarida:

qualis Gaetulae stabulantem ad confraga silvae

venator longo motum clamore leonem

exspectat firmans animum et sudantia nisu

tela premens; gelat ora pavor gressusque tremescunt,

quis veniat quantusque, sed horrida signa frementis

accipit et caeca metitur murmura cura.

(IV, 494-499)

El miedo es uno de los rasgos fundamentales en el retrato de Eteocles; especialmente en los versos 496-497 de esa imagen, que se trasponen al plano real, se puede apreciar qué lejos está el tebano del valor exigible a los héroes. Por otro lado, queremos insistir en el realismo de estos versos (como el detalle de sudar las manos por miedo) y en el análisis psicológico que hacen del personaje; podemos asegurar que éste es uno de los símiles que más directamente caracterizan a lo largo de la obra.

Por lo demás, esa comparación parece conectada con otra de Valerio Flaco, donde el rey, en la necromancia que organiza, está asustado como el león ante la incertidumbre de cómo serán los cazadores que lo cercan (por tanto, la misma imagen en la que se ha cambiado la perspectiva, en un contexto semejante:

quasi multa leo cunctatur in arta

molle virum rictuque genas et lumina pressit:

sic curae subiere ducem.

(Arg. I, 757-759)

2 Cf. Vessey, D., Statius \& the Thebaid, Cambridge, 1973, p. 144. 
Respecto al miedo del rey de Tebas, no olvidemos el símil del piloto perdido (III, 22-30) o cuando se le compara indirectamente con un cisne:

nec segnius ardens

occurrit, niveo quam flammiger ales olori

imminet et magna trepidum circumligat umbra.

(VIII, 674-676)

(obsérvese especialmente trepidum del verso 676); la comparación se produce cuando Tideo se dispone a atacarlo: por tanto, tampoco destaca el rey como guerrero. Del mismo modo, Tideo lo acosa como un lobo a un novillo:

sic densa lupum iam nocte sub atra

arcet $\mathrm{ab}$ adprenso pastorum turba iuvenco;

improbus erigitur contra, nec cura vetantis

impetere: illum, illum, semel in quem venerat, urget.

(VIII, 691-494)

Así pues, está siempre representado Eteocles por un animal inferior al atacante.

La única comparación que no le hace menoscabo es con el pastor que dispone su rebaño, cuando ordena los ejércitos para la guerra:

perspicuas sic foris et virgea pastor

claustra levat, dum terra recens; iubet ordine primo

ire duces, media stipantur plebe maritae;

ipse levat gravidas et humum tractura parentum

ubera, succiduasque adportat matribus agnas.

(VII, 393-397)

En realidad sólo se le está representando en su función de rey, sin advertirse elementos que lo engrandezcan.

Para terminar, notemos que en dos ocasiones, las comparaciones igualan a Polinices con Faetonte; la primera vez cuando Adrasto (en los juegos funerales del Libro VI) enseña a su yerno el manejo de su carro, como el Sol a su hijo:

sic ignea lora

cum daret et rapido Sol natum imponeret axi, gaudentem lacrimans astra insidiosa docebat nolentisque teri zonas mediamque polorum temperiem: pius ille quidem et formidine cauta, sed iuvenem durae prohibebant discere Parcae.

(VI, 320-325)

En la otra ocasión, Antígona y Argía lavan su cadáver como con Faetonte hicieron sus hermanas:

sic Hyperionium tepido Phaetonta sorores

fumantem lavere Pado; vix ille sepulcro

conditus, et flentes stabant ad flumina silvae.

(XII, 413-415) 
Además de la coherencia de estos dos símiles entre sí y con el personaje, es destacable la relación que se establece entre Polinices y Faetonte, ambos dominados por un poder que los obsesiona y que llegará a destruirlos. En conclusión, Faetonte es una nota más de las que se sirve Estacio para reflejar el comportamiento del príncipe destronado. 